\title{
Pathway engineering of benzylisoquinoline alkaloid biosynthesis in transgenic California poppy cells with ectopic expression of tetrahydroberberine oxidase from Coptis japonica
}

\author{
Yasutaka Matsushima ${ }^{\dagger}$, Hiromichi Minami ${ }^{\dagger}$, , Kentaro Hori, Fumihiko Sato* \\ Division of Integrated Life Science, Graduate School of Biostudies, Kyoto University, Kyoto 606-8502, Japan \\ *E-mail: fsato@lif.kyoto-u.ac.jp Tel: +81-75-753-6381 Fax: +81-75-753-6398
}

Received October 2, 2012; accepted November 1, 2012 (Edited by T. Demura)

\begin{abstract}
S)-Tetrahydroberberine oxidase is the enzyme in the last step of berberine biosynthesis. While a previous report described the isolation of cDNA of tetrahydroberberine oxidase (THBO) from cultured Coptis japonica cells, we later found that purified THBO was heavily contaminated by triosephosphate isomerase. Here, we report the re-isolation of THBO cDNA from cultured C. japonica cells and its functional characterization in transgenic California poppy cells.

A cDNA clone for $(S)$-tetrahydroberberine oxidase was isolated from an EST library prepared from high berberineproducing cultured $C$. japonica cells based on the partial amino acid sequence of the purified enzyme. Analyses of the nucleotide sequences of the cloned cDNA inserts of 1728 base pairs revealed an open reading frame that encoded a 540-amino acid polypeptide with putative 28-amino acid signal peptides and a mature polypeptide with a molecular mass of 57,748. A protein blast search also shows that CjTHBO belongs to the FAD-containing berberine bridge enzyme oxidoreductase family. Since all attempts to produce active recombinant CjTHBO in Escherichia coli and Saccharomyces cerevisiae cells failed, we tried to express CjTHBO in California poppy (Eschscholzia californica) cells. When transgenic California poppy cells that ectopically expressed CjTHBO under the control of Cauliflower mosaic virus 35S promoter were established, the transgenic cells showed small but evident new alkaloid peaks, which were scarcely detected in control cells that did not express CjTHBO. LC-MS analyses showed that these peaks were coptisine and dehydrocheilanthifoline, which were expected to be generated by the reaction of $\mathrm{CjTHBO}$ from pathway intermediates, i.e., cheilanthifoline and stylopine. The usefulness of CjTHBO for metabolic engineering in transgenic California poppy cells is discussed.
\end{abstract}

Key words: Benzophananthridine alkaloid biosynthesis, California poppy, Coptis japonica, (S)-tetrahydroberberine oxidase.

Benzylisoquinoline alkaloids (BIAs) are a large and diverse group of alkaloids with $\sim 2500$ defined structures (Liscombe et al. 2005). BIA biosynthesis begins with the conversion of tyrosine to both dopamine and 4-hydroxyphenylacetaldehyde by decarboxylation, orthohydroxylation, and deamination (Sato and Yamada 2008). Dopamine and 4-hydroxyphenylacetaldehyde are condensed by norcoclaurine synthase to yield $(S)$ norcoclaurine (Samanani et al. 2004; Minami et al. 2007), which is then sequentially converted to coclaurine by $S$ adenosyl methionine (SAM)-dependent norcoclaurine
6-O-methyltransferase (Morishige et al. 2000), to $\mathrm{N}$ methylcoclaurine by coclaurine $N$-methyltransferase (Choi et al. 2002), to $3^{\prime}$-hydroxy- $N$-methyl coclaurine by P450 hydroxylase (Pauli and Kutchan 1998), and then to (S)-reticuline by $3^{\prime}$-hydroxy $\mathrm{N}$-methylcoclaurine $4^{\prime}-\mathrm{O}$ methyltransferase (Morishige et al. 2000). (S)-Reticuline is a central intermediate for divergent BIAs, including protoberberine, aporphin, benzophenanthridine and morphinan alkaloids.

In protoberberine biosynthesis, $(S)$-reticuline is converted by berberine bridge enzyme (BBE; Dittrich

Abbreviations: BBE, berberine bridge enzyme; BIAs, benzylisoquinoline alkaloids; CaMV, Cauliflower Mosaic Virus; cDNA, complementary DNA; $\mathrm{Cj}$, Coptis japonica; DTT, dithiothreitol; Ec, Eschscholzia californica; EST, expression sequence tag; LC-MS, liquid chromatography-mass spectrometry; P450, cytochrome P450; PVDF, polyvinylidene difluoride; RT-PCR, reverse transcriptase-polymerase chain reaction; RNAi, RNA interference; SAM, $S$-adenosyl methionine; SDS-PAGE, sodium dodecyl sulfate-polyacrylamide gel electrophoresis; STOX, (S)-tetrahydroprotoberberine oxidase; THB, tetrahydroberberine; THBO, THB oxidase; TPI, triosephosphate isomerase.

${ }^{\dagger}$ These authors contributed equally to this work.

${ }^{a}$ Present address: Research Institute for Bioresources and Biotechnology, Ishikawa Prefectural University, Nonoichi-shi, Ishikawa 921-8836, Japan

This article can be found at http://www.jspcmb.jp/

Authors dedicate this article to late Dr. Naosuke Okada.

Published online December 12, 2012 
<smiles>COc1ccc(CN2CCc3cc(OC)c(O)cc3C2C)cc1</smiles>

(S)-reticuline $\mathrm{m} / \mathrm{z} 330$

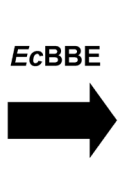

(S)-scoulerine $\mathrm{m} / \mathrm{z} 328$

\section{EcCYP719A5}

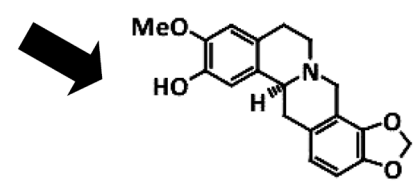

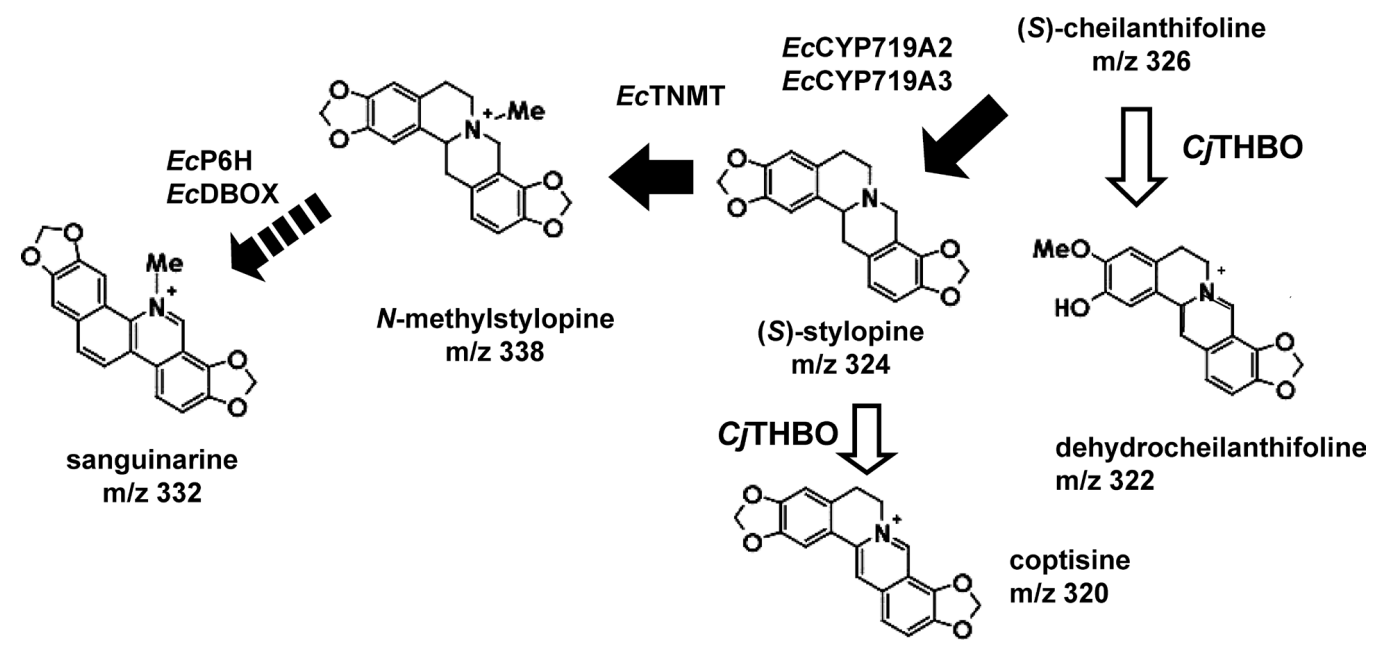

Figure 1. Metabolic pathway and predicted metabolic shift in transgenic California poppy cells that expressed CjTHBO. BBE, berberine bridge enzyme, CYP719A5, cheilanthifoline synthase, CYP719A2/A3, stylopine synthase, TNMT, tetrahydroprotoberberine N-methyltransferase; P6H, protopine 6-hydroxylase; DBOX, dihydrobenzophenanthridine oxidase.

and Kutchan 1991) to scoulerine, and then to $(S)$ tetrahydrocolumbamine by SAM-dependent scoulerine 9-O-methyltransferase (Takeshita et al. 1995), to tetrahydroberberine (THB; canadine) by a P450dependent canadine synthase (Ikezawa et al. 2003), and finally to berberine by tetrahydroberberine oxidase (THBO; Okada et al. 1988). All of the cDNAs for these reactions have been isolated and functionally expressed in microbial cells to characterize their enzymological properties, except for the enzyme in the last step THBO.

While a previous report described the isolation of cDNA of THBO from cultured Coptis japonica cells (Okada et al. 1989), we later found that the purified THBO was contaminated by triosephosphate isomerase (TPI; Sato et al. 1990). Here, we report the re-isolation of THBO cDNA from cultured Coptis japonica cells and its functional characterization in transgenic California poppy (Eschscholzia californica) cells (Figure 1).

\section{Materials and methods}

\section{Plant material and purification of THBO}

Cultured Coptis japonica cells with high berberine-producing activity were maintained as described previously (Sato and Yamada 1984). Cultured cells were harvested after 3 weeks of culture and homogenized in $100 \mathrm{mM}$ phosphate buffer $(\mathrm{pH}$ 8.0) containing $10 \mathrm{mM}$ dithiothreitol (DTT) with Polyclar AT and sea sand. The homogenate was centrifuged at $10,000 \times g$ for
$30 \mathrm{~min}$, and then fractionated with $30-75 \%$ ammonium sulfate precipitation. The precipitates were dissolved in a minimal volume of $20 \mathrm{mM}$ Tris- $\mathrm{HCl}$ buffer ( $\mathrm{pH} 7.5$ ) containing $2 \mathrm{mM}$ DTT, and then dialyzed overnight. The dialyzed extracts were applied to SP-Toyopearl 650C to remove alkaloids. The passthrough fractions were applied to Q-Sepharose FF, BioGel HTP and Mono P columns, in which THBO active fractions were eluted by $0-1 \mathrm{M} \mathrm{NaCl}, 10-400 \mathrm{mM}$ phosphate buffer $(\mathrm{pH}$ 7.0) and $25 \mathrm{mM}$ Bis-Tris ( $\mathrm{pH} 7.1) / 10 \%$ polybuffer $74(\mathrm{pH} 4.0)$ gradients, respectively. All processes for enzyme purification were performed at $4^{\circ} \mathrm{C}$.

\section{Amino acid sequence analysis}

To determine the $\mathrm{N}$-terminal amino acid sequences, $0.01 \mathrm{mg}$ of purified THBO was electro-transferred on a polyvinylidene difluoride (PVDF) membrane (Nihon Milipore, Yonezawa, Japan) from a gel after sodium dodecyl sulfate-polyacrylamide gel electrophoresis (SDS-PAGE) as described previously (Takeshita et al. 1995). A major protein band of $58 \mathrm{kDa}$ was cut from the PVDF membrane and the amino acid sequence of the peptide was determined with a protein sequencer (model 477A/120A; Applied Biosystems) as described elsewhere (Takeshita et al. 1995).

\section{cDNA isolation}

A cDNA library was constructed using poly $(\mathrm{A})^{+} \mathrm{RNA}$ isolated from 10-day-old cultured C. japonica cells as described previously (Choi et al. 2002). The cDNA library was randomly 
sequenced and an EST library was established. We searched for the candidate cDNA by using a partial amino acid sequence (SEYEGFLEXLD) of the N-terminal amino acid of purified THBO.

\section{Heterologous expression of THBO in microbial cells}

To express THBO in E. coli, full-length and N-terminal 27 amino acid-truncated cDNAs were amplified by PCR and cloned into the pCold TF vector (TAKARA), and its nucleotide sequence was confirmed by DNA sequencing. Constructs were introduced in Escherichia coli BL21 (DE3). After cells were precultured in LB medium containing $50 \mu \mathrm{g} / \mathrm{ml}$ ampicillin at $37^{\circ} \mathrm{C}$ until $\mathrm{OD}_{600}=0.4-0.6$, recombinant protein production was induced by incubation with $0.1 \mathrm{mM}$ isopropylthio- $\beta$-galactoside at $15^{\circ} \mathrm{C}$ for $24 \mathrm{~h}$. E. coli cells corresponding to $5 \mathrm{ml}$ of the culture were suspended in $50 \mathrm{mM}$ Tris- $\mathrm{HCl}$ buffer $(\mathrm{pH} 7.5)$ containing $10 \%$ glycerol and $4 \mathrm{mM} 2$-mercaptoethanol, and disrupted by sonication. Soluble and insoluble fractions were separated by centrifugation $(15,000 \times \mathrm{g})$ at $4^{\circ} \mathrm{C}$ for $15 \mathrm{~min}$ and used for a THBO assay or SDS-PAGE analysis.

\section{Transformation of California poppy cells}

Seeds of Eschscholzia californica (Takii Co., Ltd.) were sterilized and germinated on 1/2 concentration of Linsmaier-Skoog medium (Linsmaier and Skoog 1965) supplemented with $1 \%$ sucrose. Seedlings were cut into $10-\mathrm{mm}$ fragments, and then used for transformation with Agrobacterium tumefaciens LBA4404 harboring an expression vector for C. japonica THBO $(\mathrm{Cj} T H B O)$ in the dark at $25^{\circ} \mathrm{C}$. Expression vector for full-length cDNA of $\mathrm{CjTHBO}$ was constructed under a Cauliflower Mosaic Virus (CaMV) $35 \mathrm{~S}$ promoter in the binary vector pGWB2 as described previously (Takemura et al. 2010a). After 2 days of co-culture, transformants were selected on Linsmaier-Skoog medium containing $10 \mu \mathrm{M} 1$-naphthylacetic acid, $1 \mu \mathrm{M}$ benzyladenine, $50 \mu \mathrm{g} / \mathrm{ml}$ hygromycin, $100 \mu \mathrm{g} / \mathrm{ml}$ kanamycin and $200 \mu \mathrm{g} / \mathrm{ml}$ cefotaxin at $25^{\circ} \mathrm{C}$ in the dark as described previously (Takemura et al. 2010a). After 3 months of selection culture, healthy growing cells were transferred to the liquid medium without antibiotics and cultivated at $25^{\circ} \mathrm{C}$ on a shaker $(90 \mathrm{rpm})$ in the dark every 2 weeks. Transformants were characterized using genomic PCR as described previously (Takemura et al. 2010a) with specific primers; for THBO, Fw: $5^{\prime}$-ACC ATG ATG GGC ATT TCC AGT TTG GTA -3', Rv: 5' -TCA CTT CTT TGG CTTCTG CCA AAT ATCG-3'; for beta-actin Fw: 5'-GGT ATT GTG CTG GAT TCT GGT G-3', Rv: 5'-GTA GGA TTG CGT GGG GTA GTG $-3^{\prime}$.

\section{Real-time RT-PCR analysis}

To quantify the mRNA expression level of CjTHBO genes, real-time RT-PCR was performed. cDNA was prepared from transgenic cells at day 14 of culture. cDNAs of biosynthetic genes were amplified from template cDNA (final concentration $500 \mathrm{pg} / \mu \mathrm{l}$ ) with $5 \mu \mathrm{l}$ DyNAmoTM HS SYBR Green Mastermix (FINNZYMES) and specific primers (actin, Fw: 5'-GGT ATT
GTG CTG GAT TCT GGT G-3'， Rv: 5' -GTA GGA TTG CGT GGG GTA GTG -3', THBO, Fw: 5' -CCA ATG CCT TGA TCT TCG TT-3', Rv: 5' -CAA AGT CAT GAC CCC CAC TT-3'; final concentration $500 \mathrm{nM}$ ) using a DNA Engine Opticon TM System (MJ Research). After $10 \mathrm{~min}$ of denaturation at $95^{\circ} \mathrm{C}$, PCR was performed for 40 thermal cycles $\left(95^{\circ} \mathrm{C}\right.$ for $10 \mathrm{~s}, 52^{\circ} \mathrm{C}$ for $20 \mathrm{~s}$ and $72^{\circ} \mathrm{C}$ for $20 \mathrm{~s}$ ). After each run, a melting curve was obtained by heating the samples from 72 to $95^{\circ} \mathrm{C}$ to determine the specificity of amplification.

\section{Metabolite analysis by LC-MS}

Transgenic E. californica cells transformed with CjTHBO expression vector were sub-cultured in liquid medium for about one year to stabilize growth. Vector-control cell lines that expressed the beta-glucuronidase gene (G4, G5, G6 lines) and wild type (non-transformant; W2, W5, W6 lines) cells were similarly produced and maintained.

For the metabolite analysis, cultured cells were harvested at day 10 of subculture. About $0.25 \mathrm{~g}$-fresh weight of cells were extracted in $1 \mathrm{ml}$ of methanol containing $5 \mu \mathrm{l} 4 \mathrm{~N} \mathrm{HCl}$ and $100 \mu \mathrm{M}$ quinine as an internal standard at room temperature for overnight (Takemura et al. 2010b). Simultaneously, metabolites in culture medium were recovered with Sep-Pak C18 cartridges (Waters) and eluted with methanol. Metabolites were analyzed by an LC-10A system and LC-MS 2010 (Shimadzu) under the following conditions; column; TSK-gel ODS80Ts $4.6 \mathrm{~mm} \times 25 \mathrm{~cm}(\mathrm{TOSOH})$, acetonitrile $/ \mathrm{H}_{2} \mathrm{O}$ solvent gradient containing $0.05 \%(\mathrm{v} / \mathrm{v})$ trifluoroacetic acid; $45 \%$ for the first $15 \mathrm{~min}$, then 45 to $80 \%(\mathrm{v} / \mathrm{v})$ for the next $3.5 \mathrm{~min}$, hold at $80 \%$ for $6 \mathrm{~min}$, and then maintain re-equilibrium at $45 \%$ for $5 \mathrm{~min}$. Flow speed; $0.5 \mathrm{ml} / \mathrm{min}$, column temperature, $40^{\circ} \mathrm{C}$; analytical mode; SIM-SCAN(+), Q-array voltage; $100 \mathrm{~V}$.

Berberine and chelerythrine were purchased from Wako Pure Chemicals, and sanguinarine, protopine, and allocryptopine were obtained from SIGMA-ALDRICH Co. (St. Louis, MO). (S)-Reticuline and $(S)$-scoulerine were gifts from Mitsui Chemicals Inc. (Tokyo, Japan). $(R, S)$ Tetrahydroberberine was prepared from berberine as described previously (Yamada and Okada 1985). All other chemicals were of the highest purity available.

\section{THBO assay}

THBO activity was measured in $100 \mathrm{mM}$ potassium phosphate $(\mathrm{pH} 7.0), 0.4 \mathrm{mM}(R, S)-\mathrm{THB}$ and the enzyme preparation at $30^{\circ} \mathrm{C}$ for $60 \mathrm{~min}$. After the enzyme reaction, proteins were denatured with methanol and the reaction product was analyzed by LCMS-2010 (Shimadzu).

The protein concentration was determined according to Bradford (1976) with bovine serum albumin as the standard.

\section{Alignment analysis}

The nucleotide sequence was deposited in DDBJ/GenBankTM (AB564543) and aligned using Clustal W (http://www.genome. jp/tools/clustalw/). The GenBank accession numbers for the sequences used are BsBBE (AF049347), AmBBE (EU881889), 


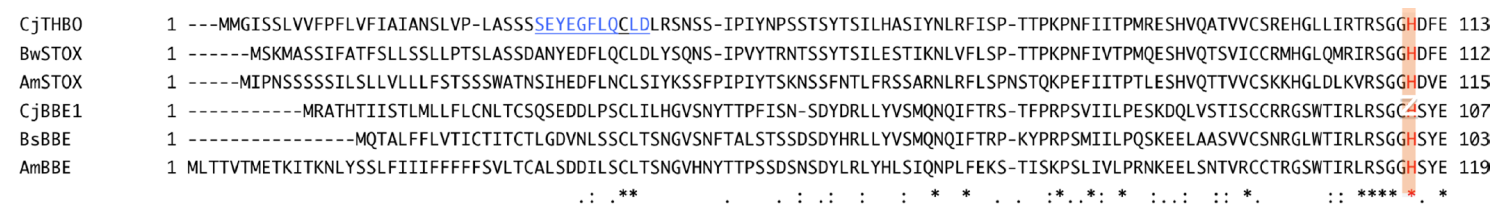

CjTHBO 114 GSSFVATVPFVLLDLIHLRTISVNIEDETAWVQTGATIGELYYRIAEKSR-THAFPAGLCPSVGVGGHSGAGYGILMRKYGLSADHVIDARLVDVNGRILDKESMGEDYFWAIRGGGGA 233 BWSTOX 113 GLSYVSNVPFVVLDLIHLKTINVDIEENSAWVQTGATIGELYYRIAEKVG -VHAFPAGLCPTVGVGGHISGAGYGVLMRKYGVSADHVIDARIVNVDGEILDRESMGEDLFWAIRGGGGA 231 AmSTOX 116 GLSYVSDSPYVMIDLVDFRNITVNVKNATAWIQAGSSLGEVYYKVGNESKNTLGFPAGF CPTVGVGGHISGGGGGSLVRKYGLASDQVIDARIVTVNGEILNKETMGKDLYWAIRGGGAN 235 CjBBE1 108 GLSHTADSPFVIIDMMNLNGVSIDLDTQTAWAESGATLGEIYHAIGVSSD -VLGFSAGYFTTVGSGGHSGGGFGMMSRYGLAADNVVDAILISANGALYDRKSMGEDVFWAIRGGGGG 226 BSBBE 104 GLSYVADTPFVVIDLMNLNRISIDLESKTAWVESGATLGEIYCAISEASD -TLGFSGGYCPTVGSGGHISGGGFGMMSRKYGLAADNVIDALIVDANGAVLDRSSMGEDVFWAIRGGGGG 222 AmBBE 120 GLSYTADTPFVLIDLMNLNRISIDIDSETAWVESGATLGELYYAITELTD -SLGFTAGWCPTVGSGGHISGGGFGMMSRKYGLAADNVEDVILIDSKGAILDRKLMGEDVFWAVRGGGGG 238

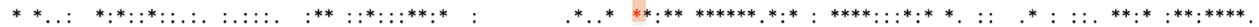

CjTHBO 234 SFGVILAWKIRLVPVPPTVTTFVVPRVLE - QGATALVHKWQIIADKLDDDLFLGLSVQALHLDPDHPEKKTIVISFLGFYLGAPEKTLQLMEESFPELGLMKEDCIEMSWIKSALYFGI 351 BWSTOX 232 SFGVILAWKIRLVPVPPTVTIFIVPKTLE -EGATALLHKWOFIGDNVHEDLFIGLSMRSVIISPKG—DKTILVSFIGLFLGGSDKLVOHMEOSFPELGVKPHDCIEMSWIKSTVVFGV 347 AmSTOX 236 NFGVLLSWKVKLVPVTPIVTVATIDRTLE-QGATNLVHKWQFVADRLHEDVYIGLTMVTANTSRAG—EKTVVAQFSFLFLGNTDRLLQIMEESFPELGLKRNDTTEMSWVESHVYFYR 351 CjBBE1 227 VWGVVYAWKLQLLPVPKHVTVFKLTKHTSEIDEASKLLYKWQLVAPNLDDDFSLAVNG ------AEKDGFWLTFLGLYLGPKEVAVSSMHQKFPELNLLSEECKEVSWVEAFAQLAG 337 BSBBE 223 VWGAIYAWKLQLLPVPKQVTVFKLMKNFDNIEEASKMLHKWQVVAPALEDDFTLSVLAG------ADTNGIWFSFLGLYLGPKELAISSVDQNFPELNLVMEDCKEMSWVESFAHLAG 334 AmBBE 239 VWGAIYAWKIKLLPVPKKVTVFRVTKNVN -IEEASFLIHKWQYVADELDDDFTVSILGG-_-_-_-ANGNEVWVIFLGLHLGCKTVAKSIIDKKFPELGLIEEEFLEMNWGESFAYLSG 349

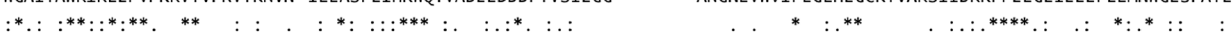

CjTHBO 352 FQLETDLSLLLERKNPIPPKNRYMSKSDYVHEPVSEAVLEGIWKRFN —EVDEPEIIMSPYGGKMNEIEESAIAFPHRKGNMYKINYLVSWKELGEEAEKKHASWIRELYNYMTPYVSKN 469 BWSTOX 348 FSNDASLSVLLDRKNPFPPKSYHKVKSDYVTEPLPISVLEGICHRFLKNGVNKAEIIMSPYGGRMNEISESEIAFPHRKGNLYKINYIAEWEEAGSMEN —HLSWIRELYRYMTPYVSKS 465 AmSTOX 352 RGQPIEFLWDRDHLT----KSFLKVKSDYVREPISKLGLEGIWKRYVG-GDSPAMLWTPFGGRMNQISEFESPYPHRAGNIYNIMYVGNWLNENESEK-QLNWMRSFYSYMGRYVSKN 463 CjBBE1 338 ----LKEVDELNNRFLKYDDRAFKTKVDFAEVPIPLEGINGALOILKK-EORGFMVMNGOGGMMGRISRDSIPFPHRSGMLSMIEYIVAWDMDEDFNSHEYINWLHOFYDYMGOFVGNN 451 BSBBE 335 ----LNSVEEMNNRFLKYDDRAFKTKVDFVKEPIPLEGIKGALTMLTK-ELRGFMAFNGQGGLMSRISSDSTPFPHRKGTLMMMEYIVAWDRDEDAKSYEFIGWLHGFYNYMGQFLPSD 448 AmBBE 350 ----LKTVKELNNRFLKFDDRAFKTKVDFTKETLPLEAIDGLLEILSK-EPRGFIALNGFGGKMSKISNDFTPFPHRKGTKLMVEYIVAWSKDEESKSDEFFDWLRNIYDYMEMFVSKN 463

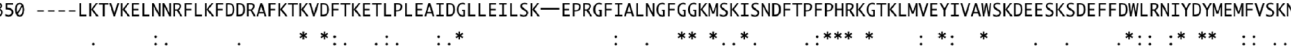

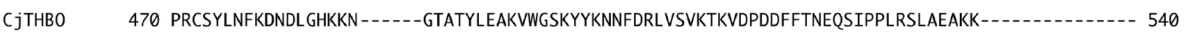
BWSTOX 466 PRSSYLNFKDIDL GQTKN---.-GTATYSQAKAWGSKYFKNNFKRLMOVKTKVDPNNFFCNEQGIPPFSSAmSTOX 464 PRSAYLNYKDLDLGVNDNNV---SEYIRYLKARSWGRKYFKNNFEKLVKVKSMVDPDNFFKNKQSIPPIRSWGKELEAINIVI---- 543 CjBBE1 452 PRVGYVNHVDFDFGTIDWTNSSISASKAIEIARTWGEKYFLSN YDRLVGAKTLIDPNNVFSHPQSIPPLHRGVGCRGNIVI--.-.- 532 BSBBE 449 PRIAYVNHVDLDLGRLDWTN-STIASNAIEIARTWGEKYFLSNYERLVRAKTLIDPKNVFHHPQSIPPMPQDDLRPNGIWRTEEMFFLE--- 536 AmBBE 464 PRVGYVNHIDLDLGGIDWSD-KNSSNNAIEIARNWGEKYFLSNYERLIRAKTLIDPNNVFNHPQSIPPMMKYYNVDDEKNLKLHVDQGNVIF 554

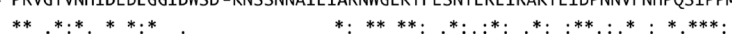

Figure 2. Alignment of CjTHBO, STOX and berberine bridge enzymes (BBE). The predicted protein sequence of CjTHBO was aligned with BwSTOX (HQ116697), AmSTOX (HQ116697), CjBBE (AB747097), BsBBE (AF049347) and AmBBE (EU881889) using Clustal W. *, :, and . indicate identical, highly homologous and homologous residues among these amino acid sequences. Highlighted (red) histidine and cysteine residues have been reported to bind FAD bicovalently in E. californica BBE (Winkler et al. 2008). Underlined (blue) residues are an N-terminal amino acid sequence determined with purified CjTHBO.

CjBBE (AB747097), BwSTOX (HQ116697), and AmSTOX (HQ116697).

\section{Results}

\section{Isolation of cDNA for THBO}

In our previous report (Okada et al. 1989), we purified THBO 10.8-fold from cultured C. japonica cells, but this purified fraction was contaminated with triosephosphate isomerase (TPI; Sato et al. 1990). Thus, we re-purified THBO from cultured C. japonica cells as described in the Materials and methods. Based on a detailed analysis of the chromatographic elution profile and enzyme activity, we estimated that THBO was a polypeptide of $58 \mathrm{kD}$ (data not shown). To obtain molecular information on THBO, purified THBO was blotted on PVDF membranes and its $\mathrm{N}$-terminal amino acid sequence was determined to be SEYEGFLEXLD.

Since the determined N-terminal amino acid sequence was too short to prepare primers for PCR amplification, we searched an EST library with this sequence. One EST clone had an identical sequence with partial amino acids, and we tried to isolate full-length cDNA.

\section{Nucleotide sequence and predicted amino acid sequences}

The isolated cDNA clone contained 1728 nucleotides with an open reading frame that encoded 540 amino acids. SignalP (http://www.cbs.dtu.dk/services/SignalP/) predicted a 28 signal peptide at the $N$-terminal end and ExpasyAU analysis (http://au.expasy.org/tools/pi_tool. $\mathrm{html}$ ) of the mature protein predicted a molecular mass of 57,748 with pI 6.1. (DDBJ/Genbank/EMBL accession number AB564543) (Figure 2).

Using the deduced amino acid sequence, we searched for homologous sequences in the DDBJ/Genbank database using the BLAST search program (http://blast. ncbi.nlm.nih.gov/Blast.cgi). The first protein BLAST search (in 2010 when AB564543 was registered) showed that the deduced amino acid sequence of mature protein had an overall high similarity to berberine bridge enzyme from Berberis stolonifera (40\% identity, Figure 2A), but we later found that our sequence was very similar to those of (S)-tetrahydroprotoberberine oxidase (STOX) of Berberis wilsonae (HQ116697; 69\% identity, Figure 2A, Gesell et al. 2011) and Argemone mexicana (HQ116698; $51 \%$ identity, Gesell et al. 2011), both of which were 
recently characterized to be the said enzyme. A protein blast search also showed that STOX and our isolated putative THBO clone contained the same FAD-binding and BBE superfamily domains as other STOXs.

\section{Expression of the recombinant polypeptide and its THBO activity}

While sequence information supported the notion that our isolated cDNA would be CjTHBO, we tried to express recombinant $\mathrm{Cj}$ THBO protein to confirm its enzyme activity in either $E$. coli or $S$. cereviciae cells. However, neither system was effective for producing active THBO (data not shown). In fact, even if we could produce soluble protein in E. coli using pCold TF vector (data not shown), large amounts of the resulting recombinant protein did not show any THBO activity. Although we made considerable effort to express enzymologically active THBO activity, we did not observe any THBO activity at all (data not shown). Thus, we finally decided to transform California poppy cells, which usually do not accumulate protoberberine alkaloids, but rather produce benzophenanthridine alkaloid through protoberberine intermediates.

\section{Establishment of transgenic California poppy cells with the overexpression of CjTHBO}

Expression vector for full-length cDNA of putative THBO from C. japonica $(C j T H B O)$ was constructed under the control of CaMV 35S promoter. Next, 165 segments of California poppy seedlings were infected with Agrobacterium tumefaciens. After serial selection, about 40 kanamycin/hygromycin-resistant clones of CjTHBO transformants were established. When we analyzed 19 transgenic cell lines with genomic PCR, all of the clones clearly showed the successful integration of CjTHBO transgene (Figure 3). Finally, 15 clones of CjTHBO transformants were selected for the analysis of the expression of $C j T H B O$.

Further RT-PCR analysis of transgenic California poppy cells with $C j T H B O$ transgenes clearly showed the accumulation of $C j T H B O$ transcripts, whereas wild type and GUS vector-control cells did not show any transcripts of CjTHBO (Figure 4). Among transgenic California poppy cells with $C j T H B O, T 1, T 6, T 28$, and T42 showed relatively high expression. To compare the effects of CjTHBO expression in transgenic California poppy cells, lines T3, T7 and T37 were also selected as low $\mathrm{Cj}$ THBO-expressing lines.

\section{Alkaloid profile analysis in transgenic California poppy cells}

To characterize the effects of $\mathrm{CjTHBO}$ expression on alkaloid biosynthesis, alkaloid profiles in cell extract and culture medium were compared among CjTHBOexpressing, vector-control and non-transformed
A

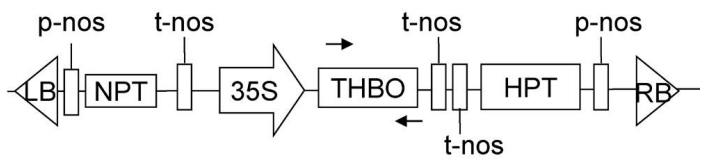

B
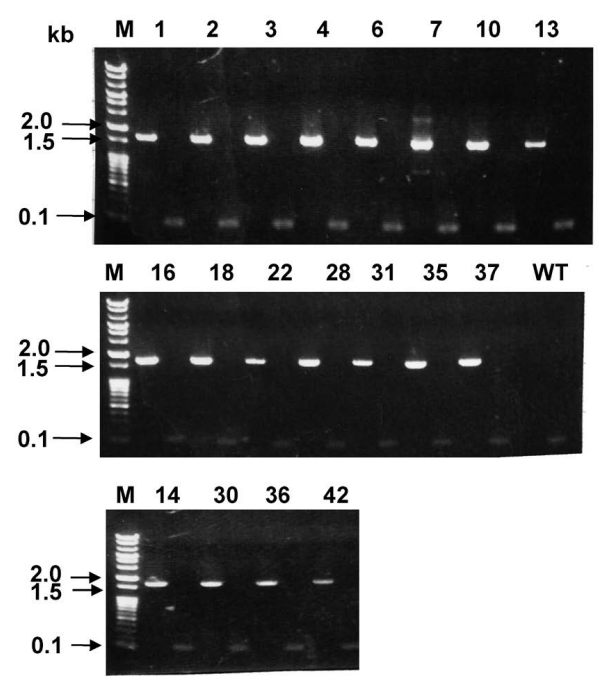

Figure 3. Genomic PCR analysis of CjTHBO transformants. A. Structure of expression vector. B. Genomic PCR of CjTHBO transformants. All CjTHBO transformants showed a $1.6 \mathrm{~kb}$ DNA amplification product, whereas non-transformant (WT) showed no product band.

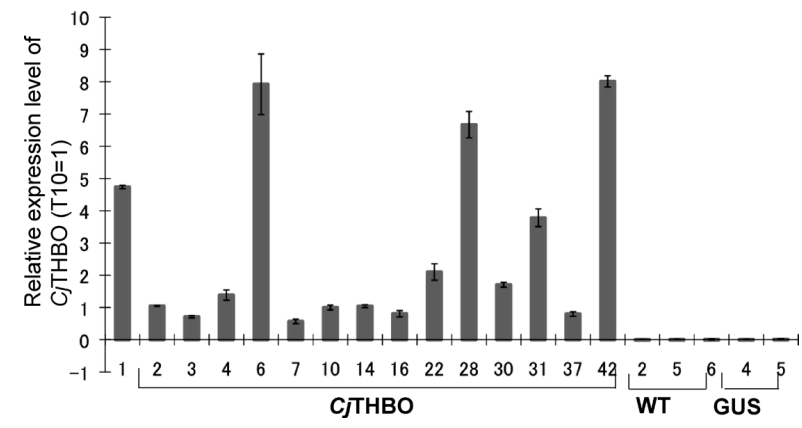

Figure 4. СjТНВО expression in transgenic California poppy cells. The accumulation of $C j T H B O$ transcripts was evaluated with real-time PCR and their relative values were corrected by the expression level of beta-actin. The relative expression level is shown as $\mathrm{T} 10=1$.

California poppy cells. Whereas all of the cells and culture medium showed similar metabolite profiles, transgenic California poppy cells with $\mathrm{Cj} T H B O$ showed novel peaks (peaks a and $\mathrm{b}$ in Figure 5A, B), in addition to peaks 1-6. Peaks 1-6 were identified by LC-MS analysis to be protopine $(\mathrm{m} / \mathrm{z} 354)$, allocryptopine $(\mathrm{m} / \mathrm{z}$ $370)$, sanguinarine $(\mathrm{m} / \mathrm{z} 332), 10$-hydroxychelerythrine $(\mathrm{m} / \mathrm{z} 364)$, chelerythrine $(\mathrm{m} / \mathrm{z} 348)$, and chelirubine $(\mathrm{m} / \mathrm{z}$ 362) based on a comparison of their retention times and mass fragment patterns with those of reference compounds. Peaks a and b were also identified as dehydrocheilanthifoline $(\mathrm{m} / \mathrm{z} 322)$ and coptisine $(\mathrm{m} / \mathrm{z}$ 320) (Figure 6).

Since dehydrocheilanthifoline and coptisine can be 


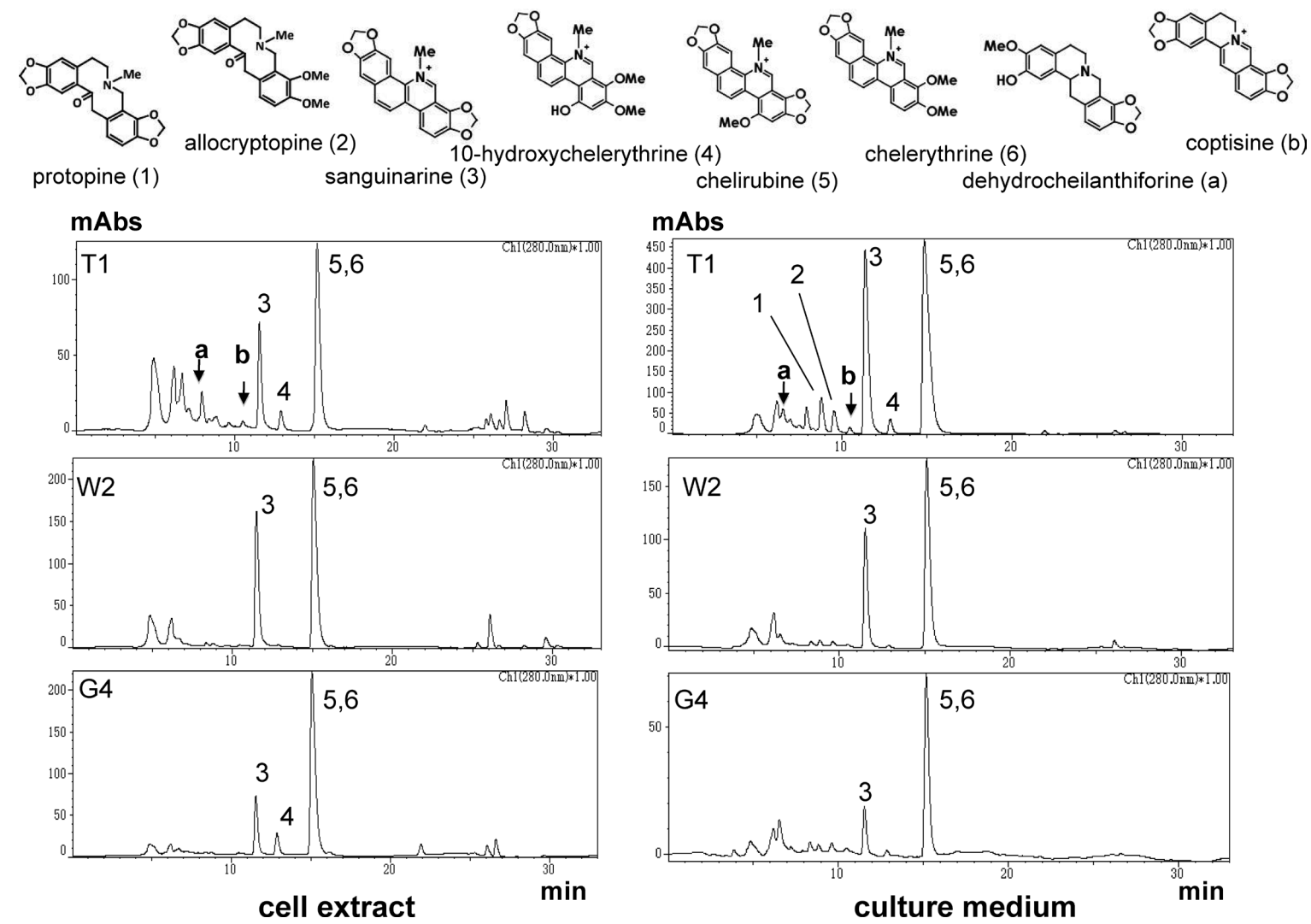

Figure 5. HPLC analysis of cell extract and culture medium of CjTHBO (T1), wild type (W2) and vector control line (G4). The results of representative cell lines are shown. Peaks were identified by LC-MS analysis as follows: 1, protopine; 2, allocryptopine; 3, sanguinarine; 4, 10-hydroxychelerythrine; 5 , chelirubine; 6 , chelerythrine. Peaks a and b were identified as dehydrocheilanthifoline and coptisine by LC-MS as shown in Figure 6.

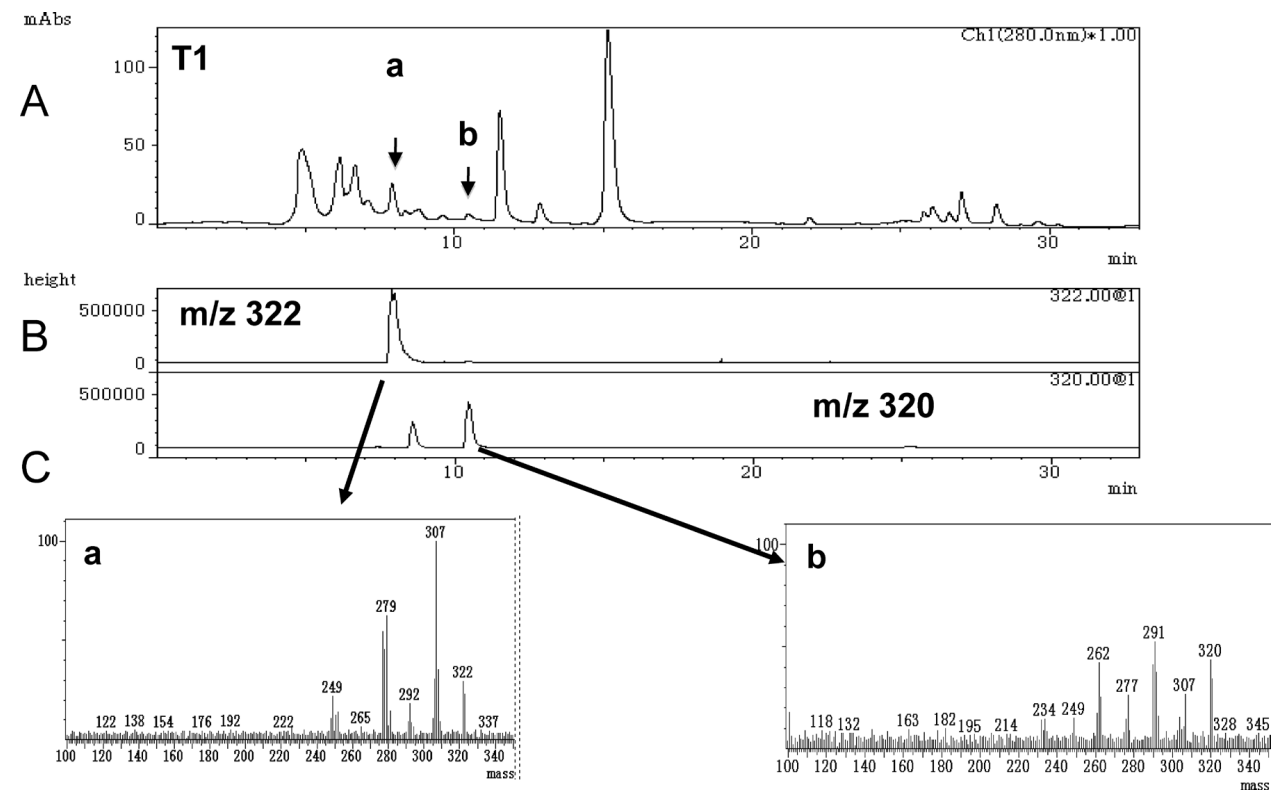

Figure 6. LC-MS analysis of novel alkaloids found in transgenic California poppy cells with CjTHBO expression. Mass fragment pattern of peaks a and $\mathrm{b}$ were identical to dehydrocheilanthifoline and coptisine.

produced by the oxidation of cheilanthifoline $(\mathrm{m} / z$ 326) and stylopine $(\mathrm{m} / \mathrm{z} 324)$, which are intermediates of benzophenanthridine alkaloid biosynthesis in California poppy (Figure 1), it was speculated that CjTHBO functioned in the alkaloid biosynthetic pathway of transgenic California poppy cells and modified the 
metabolic flow. To confirm this speculation, we evaluated the effects of $\mathrm{CjTHBO}$ expression on alkaloid profiles of high (T1, T6, T28, T42) and low (T3, T7, T37) CjTHBOexpressing lines in comparison with those in a vector control and non-transformant.

Coptisine accumulation was mainly observed in cell extracts and culture medium of high CjTHBO-expressing cells (T1, T6, T28, T42). Dehydrocheilanthifoline accumulation was also mainly observed in those of high $\mathrm{Cj} \mathrm{THBO}$-expressing cells, whereas these two alkaloids showed different accumulation trends in high $\mathrm{CjTHBO}$-expressing cells; T1 accumulated more dehydrocheilanthifoline than coptisine, but T42 accumulated more coptisine than dehydrocheilanthifoline (Figure 7). A low CjTHBOexpressing cell line (T37) showed a similar level of accumulation of coptisine as high $\mathrm{Cj} \mathrm{THBO}$-expressing cells, and vector control lines (G4 and G5) showed the marginal but evident accumulation of coptisine and/or dehydrocheilanthifoline. While further careful studies are needed to understand the accumulation of coptisine in vector controls, it is clear that $\mathrm{Cj} T H B O$ expression is highly correlated with the accumulation of oxidation products of pathway intermediates.

\section{Discussion}

We isolated cDNA for (S)-tetrahydroberberine oxidase from C. japonica cells. While this enzyme cDNA was previously reported to be isolated from this plant species (Okada et al. 1989), it was triosephoshate isomerase (TPI). Recently, Chen et al. (2012) reported the functional expression of THBO isolated from Corydalis saxicola using a Coptis triosephosphate isomerase cDNA (CjTPI) sequence. However, we did not detect THBO activity using recombinant CjTPI expressed in E. coli (Sato et al. 1990). In fact, it is very difficult to measure THBO activity since the substrate THB is easily oxidized and THBO is very unstable. Similarly, a recent report by Gesell et al. (2011) on the functional characterization of STOX isolated from Berberis and Argemone indicated that these recombinant STOXs were also very unstable and enzyme activities could only be measured with transgenic Spodoptera frugiperda Sf9 insect cells without enzyme extraction.

While our unsuccessful attempt to express CjTHBO in microbial cells illustrates the difficulties of handling THBO in vitro, it also provided some additional information on the instability of STOX/THBO. When CjTHBO was expressed in E. coli cells, recombinant proteins of $58 \mathrm{kD}$ were often found to exist as $28 \mathrm{kD}$ fragments, which Okada et al. (1988) reported as a THBO monomer in SDS-PAGE. On the other hand, when СјТНВО was expressed as a soluble form using pCold TF vector, it did not show THBO activity and no
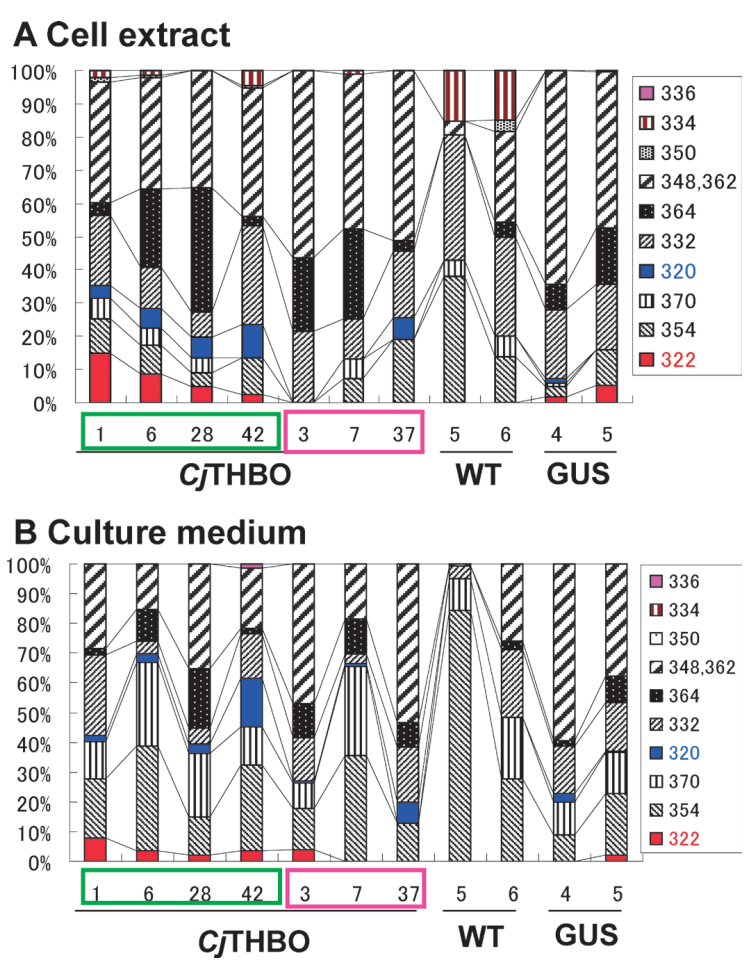

Figure 7. Alkaloid profiles in transgenic California poppy cells. A. Alkaloid profiles in cell extracts, B. Alkaloid profiles in culture media. Lines 1, 6, 28, and 42 of CjTHBO transformants were high CjTHBOexpressing, while lines 3, 7, 37 were low $\mathrm{CjTHBO}$-expressing. Lines 5 and 6 of non-transformants (WT) and lines 4 and 5 of vector control transformants (GUS) were similarly analyzed. Alkaloid content was estimated using absorbance at $280 \mathrm{~nm}$, and relative contents were calculated. $m / z$ 322, dehydrocheilanthifoline (expected THBO reaction product of cheilanthifoline in Figure 6), $m / z$ 354, protopine; $\mathrm{m} / \mathrm{z} 370$, allocryptophine; $\mathrm{m} / \mathrm{z} 320$, coptisine (expected THBO reaction product of stylopine in Figure 6); $m / z$ 332, sanguinarine; 364, 10-hydroxychelerythrine; 348 , chelerythrine; 362 , chelirubine; 370 , dihydrochelerythrine; $m / z$ 334, dihydrosanguinarine.

specific UV spectrum for flavin, while purified STOX from Berberis wilsoniae had evident flavin-specific absorbance (Amann et al. 1988) and all of the deduced amino acid sequences of STOX and THBO showed the presence of FAD-binding domain. These results highlight the difficulty of expressing STOX/THBO in an E. coli system, while some flavin-binding enzymes have been successfully expressed in E. coli (e.g., YUCCA, Mashiguchi et al. 2011).

Our transgenic California poppy cells made it possible to overcome these difficulties in characterizing CjTHBO in vitro. Transgenic California poppy cells showed modified alkaloid profiles and accumulated coptisine and dehydrocheilanthifoline, oxidized products of stylopine and cheilanthifoline. While characterization of the substrate specificity of CjTHBO has been limited (Yamada and Okada 1985, Okada et al. 1988), it is highly probable that CjTHBO functions in the alkaloid pathway in California poppy and produces coptisine and dehydrocheilanthifoline. On the other hand, purified 
STOX from B. wilsoniae showed considerably broad substrate specificities for protoberberines and simple benzylisoquinoline alkaloids (Amann et al. 1988). Recombinant STOX from B. wilsoniae expressed in insect cells also showed a similar broad substrate specificity for canadine, tetrahydropalmatine and scoulerine (Gesell et al. 2011). The detection of limited oxidized products of protoberberines in transgenic California poppy cells indicates that CjTHBO is more substrate specific. STOX from A. mexicana also showed slightly different substrate specificities. These three enzymes should be useful materials for understanding the reaction specificities of STOX/THBO.

THBO is the enzyme in the last step of berberine biosynthesis. Thus, we usually think that THBO would be useless for metabolic engineering in the alkaloid pathway (Sato et al. 2007). However, our results clearly suggest that even the last step in a pathway may play a role in some other pathway if the substrates of the enzyme are available. Conversely, STOX/THBO expression in California poppy cells would inhibit the production of benzophenanthridine alkaloid, since the intermediate might be consumed. Further studies on the distribution and regulation of gene expression of STOX/ THBO in BIA-producing plant species could help us to understand the evolution of the protoberberine and benzophenanthridine pathways.

\section{Acknowledgments}

We thank Mr. Norimatsu Takeshita and Drs. John H. Fitchen, Nobuhiko Kato and Takeshi Morishige for help in purifying THBO from cultured C. japonica cells and expressing CjTHBO in microbial cells. We are also grateful to Mitsui Chemicals Inc. for the generous gifts of the alkaloids. This research was supported by the Ministry of Education, Culture, Sports, Science and Technology of Japan [Grant-in-Aid (No. 21248013 to F. S.)].

\section{References}

Amann M, Nagakura N, Zenk MH (1988) Purification and properties of $(S)$-tetrahydroprotoberberine oxidase from suspension-cultured cells of Berberis wilsoniae. Eur J Biochem 175: $17-25$

Bradford MM (1976) A rapid and sensitive method for the quantitation of microgram quantities of protein utilizing the principle of protein-dye binding. Anal Biochem 72: 248-254

Chen K, Ye J, Liu C, Di P, Chen JF, Xiao Y, Li HL, Zhang WD (2012) Molecular characterization, recombinant expression in Escherichia coli and biological activity of $(S)$ Tetrahydroberberine oxidase from Corydalis saxicola Bunt. Mol Biol Rep 39: 3319-3326

Choi KB, Morishige T, Shitan N, Yazaki K, Sato F (2002) Molecular cloning and characterization of coclaurine $N$-methyltransferase from cultured cells of Coptis japonica. J Biol Chem 277: 830-835

Dittrich H, Kutchan TM (1991) Molecular cloning, expression, and induction of berberine bridge enzyme, an enzyme essential to the formation of benzophenanthridine alkaloids in the response of plants to pathogenic attack. Proc Natl Acad Sci USA 88:
9969-9973

Gesell A, Chávez ML, Kramell R, Piotrowski M, Macheroux P, Kutchan TM (2011) Heterologous expression of two FADdependent oxidases with $(S)$-tetrahydroprotoberberine oxidase activity from Argemone mexicana and Berberis wilsoniae in insect cells. Planta 233: 1185-1197

Ikezawa N, Tanaka M, Nagayoshi M, Shinkyo R, Sakaki T, Inouye K, Sato F (2003) Molecular cloning and characterization of CYP719, a methylenedioxy bridge-forming enzyme that belongs to a novel P450 family, from cultured Coptis japonica cells. J Biol Chem 278: 38557-38565

Liscombe DK, MacLeod BP, Loukanina N, Nandi OI, Facchini PJ (2005) Evidence for the monophyletic evolution of benzylisoquinoline alkaloid biosynthesis in angiosperms. Phytochemistry 66: 2501-2520

Linsmaier EM, Skoog F (1965) Organic growth factor requirements of tobacco tissue cultures. Physiol Plant 18: 100-127

Mashiguchi K, Tanaka K, Sakai T, Sugawara S, Kawaide H, Natsume M, Hanada A, Yaeno T, Shirasu K, Yao H, McSteen P, Zhao Y, Hayashi K, Kamiya Y, Kasahara H (2011) The main auxin biosynthesis pathway in Arabidopsis. Proc Natl Acad Sci USA 108: 18512-18517

Minami H, Dubouzet E, Iwasa K, Sato F (2007) Functional analysis of norcoclaurine synthase in Coptis japonica. J Biol Chem 282: 6274-6282

Morishige T, Tsujita T, Yamada Y, Sato F (2000) Molecular characterization of the $S$-adenosyl-L-methionine: $3^{\prime}$-hydroxy$\mathrm{N}$-methylcoclaurine $4^{\prime}$-O-methyltransferase involved in isoquinoline alkaloid biosynthesis in Coptis japonica. J Biol Chem 275: 23398-23405

Okada N, Shinmyo A, Okada H, Yamada Y (1988) Purification and characterization of $(S)$-tetrahydroberberine oxidase from cultured Coptis japonica cells. Phytochemistry 27: 979-982

Okada N, Koizumi N, Tanaka T, Ohkubo H, Nakanishi S, Yamada $\mathrm{Y}$ (1989) Isolation, sequence, and bacterial expression of a cDNA for $(S)$-tetrahydroberberine oxidase from cultured berberineproducing Coptis japonica cells. Proc Natl Acad Sci USA 86: $534-538$

Pauli HH, Kutchan TM (1998) Molecular cloning and functional heterologous expression of two alleles encoding (S)-Nmethylcoclaurine $3^{\prime}$-hydroxylase (CYP80B1), a new methyl jasmonate-inducible cytochrome P-450-dependent monooxygenase of benzylisoquinoline alkaloid biosynthesis. Plant J 13: 793-801

Samanani N, Liscombe DK, Facchini PJ (2004) Molecular cloning and characterization of norcoclaurine synthase, an enzyme catalyzing the first committed step in benzylisoquinoline alkaloid biosynthesis. Plant J 40: 302-313

Sato F, Yamada Y (1984) High berberine-producing cultures of Coptis japonica cells. Phytochemistry 32: 659-664

Sato F, Fitchen JH, Takeshita N, Hashimoto T, Okada N, Yamada Y (1990) Synthesis of plant triosephosphate isomerase in Escherichia coli. Agric Biol Chem 54: 2189-2191

Sato F, Inui T, Takemura T (2007) Metabolic engineering in isoquinoline alkaloid biosynthesis. Curr Pharm Biotechnol 8: 211-218

Sato F, Yamada $\mathrm{Y}(2008)$ Engineering formation of medicinal compounds in cell cultures. In: Bohnert HJ, Nguyen H, Lewis NG (eds) Advances in Plant Biochemistry and Molecular Biology. vol 1. Elsevier, Amsterdam, pp 311-345

Takemura T, Chow Y-L, Todokoro T, Okamoto T, Sato F(2010a) Overexpression of rate-limiting enzymes to improve alkaloid 
productivity. In: Fett-Neto AG (ed) Plant Secondary Metabolism Engineering (Methods in Molecular Biology 643): Methods and Protocols. Humana Press, pp 33-45

Takemura T, Ikezawa N, Iwasa K, Sato F (2010b) Metabolic diversification of benzylisoquinoline alkaloid biosynthesis through the introduction of a branch pathway in Eschscholzia californica. Plant Cell Physiol 51: 949-959

Takeshita N, Fujiwara H, Mimura H, Fitchen JH, Yamada Y, Sato F (1995) Molecular cloning and characterization of S-adenosyl-
L-methionine: scoulerine-9-O-methyltransferase from cultured cells of Coptis japonica. Plant Cell Physiol 36: 29-36

Winkler A, Lyskowski A, Riedl S, Puhl M, Kutchan TM, Macheroux P, Gruber K (2008) A concerted mechanism for berberine bridge enzyme. Nat Chem Biol 4: 739-741

Yamada Y, Okada N (1995) Biotransformation of tetrahydroberberine to berberine by enzymes prepared from cultured Coptis japonica cells. Phytochemistry 24: 63-65 